\title{
Percutaneous Kyphoplasty in Treating Osteoporotic Vertebral Compression Fracture With Kyphotic Deformity: A Compared Study
}

\section{Wenye Yao}

First Affiliated Hospital of Nanchang University

\section{Runsheng Guo}

First Affiliated Hospital of Nanchang University

Qi Lai

First Affiliated Hospital of Nanchang University

Bin Zhang ( $\nabla$ acker11@126.com )

First Affiliated Hospital of Nanchang University https://orcid.org/0000-0002-5876-1238

Research article

Keywords: Efficacy, Osteoporotic vertebral compression fracture, Percutaneous kyphoplasty, Unilateral approach, bilateral approach

Posted Date: August 21st, 2020

DOI: https://doi.org/10.21203/rs.3.rs-62386/v1

License: (c) (i) This work is licensed under a Creative Commons Attribution 4.0 International License. Read Full License 


\section{Abstract}

Objective: To evaluate the efficacy and safety of percutaneous kyphoplasty (PKP) for thoracolumbar osteoporotic vertebral compression fracture (OVCF) with kyphosis via unilateral versus bilateral approach.

Methods: All patients suffered OVCF with kyphosis were retrospectively reviewed. Of those, performed unilateral PKP or underwent bilateral PKP with random. The clinical and radiological data such as the correction of deformity, sagittal profle and record of the perioperative morbidity of the patients were analyzed.

Results: All patients ( $76 \pm 3.6$ years) were enrolled in this investigation, including 47 in the unilateral and 39 in the bilateral group. No significant difference in general data was detected between the two groups $(p>0.05)$. Howere, the operation time and cement amount $28.2 \pm 3.4 \mathrm{~min}, 3.8 \pm 0.6 \mathrm{ml}$ in the unilateral group, while $50.1 \pm 4.6 \mathrm{~min}, 5.4 \pm 0.5 \mathrm{ml}$ in the bilateral group, respectively $(\mathrm{P}<0.05)$.In addition, The preoperative visual analog scale(VAS) and Vertebral local kyphosis angle were $8.8 \pm 0.65$ and $16.3 \pm$ $6.5^{\circ}$ compared to last follow-up $3.15 \pm 0.78$ and $14.26 \pm 2.16^{\circ}$ in unilateral group, while $8.5 \pm 0.78$ and $16.5 \pm$ $7.1^{\circ}$ compared to last follow-up $2.66 \pm 0.86$ and $13.81 \pm 2.38^{\circ}$ in bilateral group, respectively $(P<0.05)$. Furthermore, Oswestry Disablility Index (ODI) and prevertebral height ratio in both groups were significantly different before and after surgery, but no significant difference between the two groups ( $p$ $>0.05)$.

Conclusion: Both bilateral and unilateral PKP are relatively safe and provide effective treatment for patients with painful thoracolumbar osteoporotic vertebral compression fracture with mild kyphotic deformity. However, unilateral PKP need less operation time and volume of cement.

\section{Introduction}

Osteoporosis is a global public health problem characterized by loss of bone mass and increase of skeletal fragility, which lead to a high risk of spinal osteoporotic vertebral compression fracture (OVCF)[1]. There are approximately 1.4 million people suffer OVCF every year, of these, the elderly including postmenopausal women are common.[2, 3] OVCF usually cause back pain and spinal deformities or even death in elderly populations $[4,5]$. Patients with OVCF could be managed with conservative treatments including relieve pain, bed rest, and usage of brace. The pain caused by vertebral fracture may be insufferable[6, 7]. And a long-term clinotherapy tends to various complications, such as bone loss, psychiatric disorder, and thrombogenesis [8-10]. However, conservative treatment is inapplicable to patients with spinal deformity, or people who can not bear long-term bed rest. Open surgery is a second trauma to the vulnerable patients, and the high risk of surgical instrumentation failure in patients with osteoporosis should not be ignored [11].

On basis of technical drawbacks above, with injection of polymethyl methacrylate (PMMA) into the fractured vertebral body, percutaneous kyphoplasty (PKP) and percutaneous vertebroplasty (PVP) were 
developed to treat OVCF[12-14]. Both PKP and PVP have shown effectiveness to pain relief and low complications in patients with OVCF[15-17]. Compared with PVP, PKP has a lower cement leakage rate and better kyphotic angle[13]. Hence, PKP is superior to treat OVCF with kyphotic deformity. To the best of our knowledge, there is little literature has reported the clinical outcomes for PKP in treating OVCF with kyphotic deformity. In present study, we aimed to evaluate the efficacy and safety of PKP in treating thoracolumbar OVCF with kyphosis via unilateral or bilateral approach respectively.

\section{Methods}

\section{Patients}

Between June 2016 and February 2019, 166 patients with thoracolumbar osteoporotic vertebral compression fracture and kyphotic deformity were retrospectively reviewed at our hospital. Of these, 80 (48\%) had incomplete data or follow-up were excluded, leaving 86 (52\%) were included (Table 1). Inclusion criteria were 1) patients with OVCF, 2) vertebral body collapse from $15 \%$ to $80 \%, 3$ ) thoracolumbar kyphotic angulation ,4) patient's pain resistant to analgesics for 3 weeks or more; Exclusion criteria were 1) patients with neurological deficits, 2) vertebral collapse rate $>80 \%$ or unstable fractures, 3) spondylolisthesis, 4) vertebral body with incomplete wall, 4) bleeding disorders, 5) spinal infections or tumors. We performed unilateral PKP when the height of compressed vertebra was restored to $70 \%$ normal height. If not, bilateral PKP was used to enhance the restoration of OVCF (as shown in Figure 1). All enrolled patients with kyphotic OVCF were diagnosed by clinical symptoms and signs, as well as imagings including plain film, computed tomography (CT), and magnetic resonance imaging (MRI). The mean follow-up was 19 months (range,13-34 months). This study was reviewed and approved by the Institutional Review Board of our hospital, informed consents were obtained from eligible patients.

\section{Surgical technique}

After local anesthesia, patient was placed in a prone position. Under the guidance of fluoroscopy, a Kirschner wire was percutaneously inserted to close the compressed vertebra to explore a trajectory for cement injection (orientate 10 to 11 o'clock position to left pedicle or 1 to 2 o'clock position to right pedicle). Then propeled and fixed the tip of the wire to the trailing edge of compressed vertebral body. Next, a working pin was inserted along the Kirschner wire to the front of posterior edge of compressed vertebral body by $5 \mathrm{~mm}$. Followed by inserting a balloon after drilling a balloon channel. The ideal position of the balloon should be within the first third of the vertebral body. Afterwards, contrast agent was injected and the balloon was expanded to restore the height of compressed vertebral body. The balloon pressure generally does not exceed 250 psi. Subsequently, the acrylic resin bone cement (3 to 4.5 $\mathrm{ml}$ for one side, 4 to $6.5 \mathrm{ml}$ for both sides) was injected into targeted vertebral body. Then the restoration of vertebral body and the distribution of bone cement were accessed by intraoperative fluoroscopy. In case of bilateral operations, perform the contralateral surgery in the same way. All the surgeries were performed by an experienced spine surgeon. 


\section{Evaluations of clinical outcomes}

The operative time, blood loss and the amount of cement perfusion were documented. The visual analogue scale (VAS), ODI and imagings were used to evaluate clinical outcomes preoperatively and postoperatively. Radiographic films were measured to access the height reduction of vertebral body and kyphotic angulation (Figure 2, Figure 3). The parameters above were used to evaluate technical efficacy. The leakage incidence of bone cement was used to access technical safety.

\section{Statistical analysis}

Statistical analysis was performed using the SPSS 19.0 software (SPSS, Inc., Chicago, IL, USA). The measurement data were expressed as mean \pm standard deviation $(x \pm s)$. Student's t-test and Chisquare test was used to analyze the differences between the two groups. $\mathrm{P}<0.05$ was considered statistically significant.

\section{Results}

With a mean age of $67 \pm 14$ years, 39 patients in unilateral group and 47 cases in bilateral group were finally reviewed in this retrospective study. Individual follow-up no less than 24 months. No patients died during the followup. For the unilateral group, there were 15 males and 26 females, with a mean age of $79.0 \pm 4.8$ years old. The BMI was $23.10 \pm 3.8 \mathrm{~kg} / \mathrm{m} 2$. For the bilateral group, there were 16 males and 29 females, with a mean age of $73.0 \pm 3.8$ years old. The BMI was $23.02 \pm 3.7 \mathrm{~kg} / \mathrm{m} 2$. In terms of demographic data of patients, there were no significant differences between the two groups (Table 1).

The operation time and cement amount $28.2 \pm 3.4 \mathrm{~min}, 3.8 \pm 0.6 \mathrm{ml}$ in the unilateral group, while $50.1 \pm 4.6$ min, $5.4 \pm 0.5 \mathrm{ml}$ in the bilateral group ( $P<0.05$, respectively) (Table 2$)$. The preoperative VAS and Vertebral local kyphosis angle were $8.8 \pm 0.65$ and $16.3 \pm 6.5^{\circ} \mathrm{compared}$ to last follow-up $3.15 \pm 0.78$ and $14.26 \pm 2.16^{\circ}$ in unilateral group, while $8.5 \pm 0.78$ and $16.5 \pm 7.1^{\circ}$ compared to last follow-up $2.66 \pm 0.86$ and $13.81 \pm 2.38^{\circ}$ in bilateral group, respectively $(P<0.05)$ (Table 3$)$. In addition, the ODI in both groups were significantly different before and after surgery, but no significant difference between the two groups ( $p$ $>0.05$ ). This means that both surgical methods can improve the patient's symptoms, but the bilateral surgery is better.

Most radiographic parameters showed significant prevertebral height restoration of compressed vertebra after surgery in the two groups were significantly different before and after surgery $(p<0.05$; Table 3$)$. One patient had cement leakage in unilateral group versus 3 patients in bilateral group $(2.56 \%$ vs $6.38 \%$, $p=0.747$ ). We found that There were 7 cases of cement leakage in the unilateral group (4 cases of paraspinal vein and paravertebral leakage, 2 cases of leakage into the intervertebral disc, and 1 case of slight leakage into the spinal canal; Figure 4a-c.), with an incidence rate of $14.9 \%$. In the bilateral group, there were 6 cases of cement leakage ( 3 cases of leakage along the paraspinal vein and paravertebral space, 2 cases of leakage into the intervertebral disc, and 1 case of slight leakage into the spinal canal), with an incidence rate of $15.4 \%$. These complications are consistent in PVP and PKP [20]. Moreovere, 
there was no significant difference in the bone cement leakage rate between the two groups according to Pearson $x^{2}$ test results $(P>0.05)$ (Figure $\left.4 d\right)$.

\section{Discussion}

Domestic and foreign scholars have confirmed the good therapeutic effect of PKP on OVCF $[8,10]$. Meanwhile, PKP is effective for restoring vertebral body height and correcting kyphosis and has several advantages of being minimally invasive and safe, offering rapid pain relief, and involving simple manipulation techniques[21,22]. The aim for good treatment for OVCF is supposed to achieve improvement in symptoms, kyphosis deformity correction and prevention of new fractures[23-25]. However, PKP for OVCF could be divided into unilateral and bilateral approaches. Until now, the best treatment option is still controversial for symptomatic OVCF without neurological deficits. Some authors concluded that the benefits of bilateral percutaneous kyphoplasty regarding pain relief, low rates of cement leakage, and height restoration have been documented, but several retrospective studies concluded that a unilateral percutaneous kyphoplasty might provide similar results for clinical and radiographic outcomes as bilateral percutaneous kyphoplasties[26, 27]. However, less retrospective study was proceeded to compare vertebral local kyphosis correction between the unilateral and bilateral PKP.

Our retrospective study exhibited that both unilateral and bilateral PKP markedly improved the outcome of patients with OVCF. This was reflected in considerable change in VAS and ODI as well as a significant improvement in the Kyphosisangle after treatment. However, no statistically significant differences were observed compared between the two groups at all time intervals. These results support that both unilateral and bilateral PKP were effective methods in the treatment of OVCF.

In our study, the operative time and amount of cement perfusion doses to the patient are significantly different between the unilateral and the bilateral groups. We found that the unilateral group has shorter operative time and lesser bone cement volume than the bilateral group. Besides, this means that the unilateral approach was less costly than the bilateral group, which was confirmed in a recent metaanalysis [28] and consistent with the findings of Rebolledo et al[19].Statistically significant differences were observed when the operation time and cement amount were compared between the groups.

According to the abovementioned results, unilateral PKP can effectively restore the height of the injured vertebrae, can correct the kyphosis, has shorter operative time, and can be easily performed. The contralateral bone density was increased via one-sided puncture balloon inflation. The unilateral puncture balloon inflation push increases the contralateral bone density. Although the amount of bone cement is less, it can effectively enhance the support force of the injured vertebra and achieve therapeutic effect. There was no significant height loss of the surgical vertebral body during the outpatient followup(Table 3).

In this study, the cement leakage in the unilateral level was not obviously more than that in the bilateral level. These complications may be related to the puncture errors, unclear images, and incorrect timing of 
cement perfusion. Besides, the incidence of bone cement leakage is related to the severity of vertebral fracture and the volume of balloon dilation. Most scholars believe that once the bone cement leakage is found, it is necessary to stop the injection immediately.

This study has certain limitations. First, we enrolled a relatively small number of patients. Therefore, a consecutive study is required. Second, although osteoporosis can be due to many causes before PKP, we were unable to investigate whether the cause of osteoporosis has an effect on PKP. Thus, the effect of the causes of osteoporosis was not considered in the present study.

\section{Conclusion}

Both bilateral and unilateral PKP are relatively safe and provide effective treatment for patients with painful thoracolumbar osteoporotic vertebral compression fracture with mild kyphotic deformity. However, unilateral PKP need less operation time and volume of cement.

\section{Abbreviations}

PKP: percutaneous kyphoplasty

PMMA: polymethylmethacrylate

OVCFs: osteoporotic vertebral compression fractures

PVP: percutaneous vertebroplasty

CT: computed tomography

MRI: magnetic resonance imaging

VAS: visual analog scale

BMI: body mass index

ODI:Oswestry Disablility Index

\section{Declarations}

\section{Availability of data and materials}

The detailed data and materials of this study were available from the corresponding author through emails on reasonable request.

\section{Authors' contributions}


WY and RG made the same contribution in this article,WY and RG performed all the experiments and wrote the manuscript. QL participated in the collection of experimental data. BZ guided the entire process of the experiment.All authors have read and approved the final manuscript.

\section{Acknowledgements}

No acknowledgement.

\section{Funding}

This research received funding from the National Natural Science Foundation of China (grant no. 81860405).

\section{Ethics approval and consent to participate}

Our study has been approved by the Ethics committee of The First Affiliated Hospital of Nanchang University.

\section{Consent for publication}

Consent for publication was obtained from all participants.

\section{Competing interests}

The authors declare that they have no competing interests.

\section{Footnotes}

No potential conflict of interest was reported.

\section{Publisher's note}

Springer Nature remains neutral with regard to jurisdictional claims in published maps and institutional affiliations.

\section{References}

1. Jackson SA. A.T.L.R., Vertebral Fracture De ${ }^{\circledR}$ nition from Population-Based Data: Preliminary Results from the Canadian Multicenter Osteoporosis Study (CaMos. Osteoporosis Int, 2000(11): p. 680-687.

2. Klazen $\mathrm{CA}$, et al. Vertebroplasty versus conservative treatment in acute osteoporotic vertebral compression fractures (Vertos II): an open-label randomised trial. The Lancet. 2010;376(9746):1085-92.

3. Johnell O, Kanis JA. An estimate of the worldwide prevalence and disability associated with osteoporotic fractures. Osteoporos Int. 2006;17(12):1726-33. 
4. Hasserius R, et al. Prevalent vertebral deformities predict increased mortality and increased fracture rate in both men and women: A 10-year population-based study of 598 individuals from the Swedish cohort in the European Vertebral Osteoporosis Study. Osteoporos Int. 2003;14(1):61-8.

5. Hasserius R, et al. Long-Term Morbidity and Mortality After a Clinically Diagnosed Vertebral Fracture in the Elderly-a 12- and 22-Year Follow-up of 257 Patients. Calcif Tissue Int. 2005;76(4):235-42.

6. Black DM, et al. Randomised trial of effect of alendronate on risk of fracture in women with existing vertebral fractures. Fracture Intervention Trial Research Group Lancet. 1996;348(9041):1535-41.

7. Papaioannou A, et al. Diagnosis and management of vertebral fractures in elderly adults. United States: Elsevier Inc; 2002. pp. 220-8.

8. Kallmes DF, et al. A randomized trial of vertebroplasty for osteoporotic spinal fractures. $\mathrm{N} \mathrm{Engl} \mathrm{J}$ Med. 2009;361(6):569-79.

9. Rousing R, H.K.A.M., Twelve-Months Follow-up in Forty-Nine Patients With Acute/Semiacute Osteoporotic Vertebral Fractures Treated Conservatively or With Percutaneous Vertebroplasty. Spine, 2010.

10. None, Trials of Vertebroplasty for Vertebral Fractures[J]. N Engl J Med. 2009;21(361):2097-100.

11. Chen C, et al. Kyphoplasty for chronic painful osteoporotic vertebral compression fractures via unipedicular versus bipedicular approachment: A comparative study in early stage. Injury. 2010;41(4):356-9.

12. Eck JC, et al. Comparison of vertebroplasty and balloon kyphoplasty for treatment of vertebral compression fractures: a meta-analysis of the literature. The Spine Journal. 2008;8(3):488-97.

13. Wang H, S.S.Y.F., Comparison of Percutaneous Vertebroplasty and Balloon Kyphoplasty for the Treatment of Single Level Vertebral Compression Fractures: A Meta-analysis of the Literature. Pain Physician, 2015.

14. Bernardo WM, Anhesini M, Buzzini R, Osteoporotic vertebral compression fracture - Treatment with kyphoplasty and vertebroplasty. Rev Assoc Med Bras (1992), 2018. 64(3): p. 204-207.

15. Alvarez $L$, et al., $P 22$. Percutaneous vertebroplasty: functional improvement in patients with osteoporotic compression fractures. The Spine Journal, 2003. 3(5, Supplement): p. 134-135.

16. Evans AJ. J.M.K.K., Vertebral compression fractures: pain reduction and improvement in functional mobility after percutaneous polymethylmethacrylate vertebroplasty retrospective report of 245 cases. Radiology, 2003.

17. Diamond TH, C.B.C.W.. Management of acute osteoporotic vertebral fractures: a nonrandomized trial comparing percutaneous vertebroplasty with conservative therapy. Am J Med, 2003.

18. Miler $\mathrm{M}$, et al., Lower concentration of vitamin D is associated with lower DAS28 and VAS-pain scores in patients with inflammatory rheumatic diseases treated with infliximab: a pilot study. Rheumatology international, 2020.

19. Rebolledo BJ, et al., Comparison of unipedicular and bipedicular balloon kyphoplasty for the treatment of osteoporotic vertebral compression fractures: a prospective randomised study. Bone 
Joint J, 2013. 95-B(3): p. 401-6.

20. Mathis JMBS, Percutaneous Vertebroplasty and Kyphoplasty[M]. Springer, 2006.

21. He SC. Z.B.Z.H., Percutaneous vertebroplasty for symptomatic Schmorl's nodes: 11 cases with longterm follow-up and a literature review. Pain Physician, 2017(20): p. 69-76.

22. Svensson HK, O.E.K.J.. A painful, never ending story: older women's experiences of living with an osteoporotic vertebral compression fracture. Osteoporos Int, 2016(27): p. 1729-1736.

23. Heini PF. W.B.B.U., Percutaneous transpedicular vertebroplasty with PMMA: operative technique and early results. A prospective study for the treatment of osteoporotic compression fractures. Eur Spine J. 2000;9(5):445-50.

24. Barr JD. B.M.L.T., Percutaneous Vertebroplasty for Pain Relief and Spinal Stabilization. Spine. 2000;25(8):923-8.

25. Frankel BM, Monroe T, Wang C. Percutaneous vertebral augmentation: an elevation in adjacent-level fracture risk in kyphoplasty as compared with vertebroplasty. The Spine Journal. 2007;7(5):575-82.

26. Papadopoulos EC, et al. Unipedicular balloon kyphoplasty for the treatment of osteoporotic vertebral compression fractures: early results. J Spin Disord Tech. 2008;21(8):589-96.

27. Steinmann J, et al., Biomechanical comparison of unipedicular versus bipedicular kyphoplasty. Spine (Philadelphia, Pa. 1976), 2005. 30(2): p. 201-205.

28. Lee JK, et al. Percutaneous balloon kyphoplasty for the treatment of very severe osteoporotic vertebral compression fractures: a case-control study. The Spine Journal. 2018;18(6):962-969.

\section{Tables}

Table 1

Comparison of demographic and other characteristics of patients between the two groups

\begin{tabular}{|llll|}
\hline characteristics & unilateral group & bilateral group & $P$-value \\
\hline Sex (male:fmale) & $15: 26$ & $16: 29$ & 0.942 \\
\hline Age(years) & $79.0 \pm 4.8$ & $73.0 \pm 3.8$ & 0.321 \\
\hline Body mass index $\left(\mathrm{kg} / \mathrm{m}^{2}\right)$ & $23.10 \pm 3.8$ & $23.02 \pm 3.7$ & 0.188 \\
\hline Preoperative Visual Analog Scale score & $8.8 \pm 0.65$ & $8.5 \pm 0.78$ & 0.820 \\
\hline Preoperative Vertebral local kyphosis angle $\left(^{\circ}\right)$ & $16.3 \pm 6.5$ & $16.5 \pm 7.1$ & 0.365 \\
\hline Preoperative Oswestry Disablility Index & $86.3 \pm 7.2$ & $85.4 \pm 6.3$ & 0.356 \\
\hline
\end{tabular}


Table 2

Comparison of surgical conditions between the two groups

\begin{tabular}{|c|c|c|c|c|c|c|}
\hline & Number & $\begin{array}{l}\text { operation } \\
\text { time(min) }\end{array}$ & $\begin{array}{l}\text { cement } \\
\text { amount } \\
\text { (ml) }\end{array}$ & $\begin{array}{l}\text { Vertebral local } \\
\text { kyphosis angle at the } \\
\text { last follow-up }\left({ }^{\circ}\right)\end{array}$ & $\begin{array}{l}\text { VAS score at } \\
\text { the last } \\
\text { follow-up }\end{array}$ & $\begin{array}{l}\text { ODI at the } \\
\text { last } \\
\text { follow-up }\end{array}$ \\
\hline $\begin{array}{l}\text { unilateral } \\
\text { group }\end{array}$ & 47 & $28.2 \pm 3.4$ & $\begin{array}{l}3.8 \pm \\
0.6\end{array}$ & $14.26 \pm 2.16$ & $3.15 \pm 0.78$ & $27.5 \pm 2.8$ \\
\hline $\begin{array}{l}\text { Bilateral } \\
\text { group }\end{array}$ & 39 & $50.1 \pm 4.6$ & $\begin{array}{l}5.4 \pm \\
0.5\end{array}$ & $13.81 \pm 2.38$ & $2.66 \pm 0.86$ & $26.8 \pm 2.0$ \\
\hline t value & & -24.213 & -15.327 & 0.423 & 0.336 & 1.893 \\
\hline$P$ & & $\varangle 0.05$ & $\varangle 0.05$ & $\varangle 0.05$ & $\varangle 0.05$ & $\otimes 0.05$ \\
\hline
\end{tabular}

Table 3

Radiography following unilateral/bilateral

\begin{tabular}{|lllll|}
\hline items & \multicolumn{3}{l}{ unilateral group } & \multicolumn{2}{l|}{ bilateral group } \\
\hline & Preoperative & follow-up & Preoperative & follow-up \\
\hline Vertebral local kyphosis correction & $16.3 \pm 6.5$ & $14.26 \pm 2.16$ & $16.5 \pm 7.1$ & $13.81 \pm 2.38$ \\
\hline VAS $\left(^{\circ}\right)$ & $8.8 \pm 0.65$ & $3.15 \pm 0.78$ & $8.5 \pm 0.78$ & $2.66 \pm 0.86$ \\
\hline ODI & $86.3 \pm 7.2$ & $27.5 \pm 2.8$ & $85.4 \pm 6.3$ & $26.8 \pm 2.0$ \\
\hline Prevertebral height ratio(\%)* & $1.3 \pm 0.3$ & $1.1 \pm 0.2$ & $1.5 \pm 0.4$ & $1.0 \pm 0.1$ \\
\hline $\begin{array}{l}\text { Prevertebral height ratio(\%)* :The sum of the heights of the leading edge of the upper and lower } \\
\text { vertebral bodies of the injured vertebra is compared with the height of the leading edge of the injured } \\
\text { vertebra. }\end{array}$ & & & & \\
\hline
\end{tabular}

Figures 


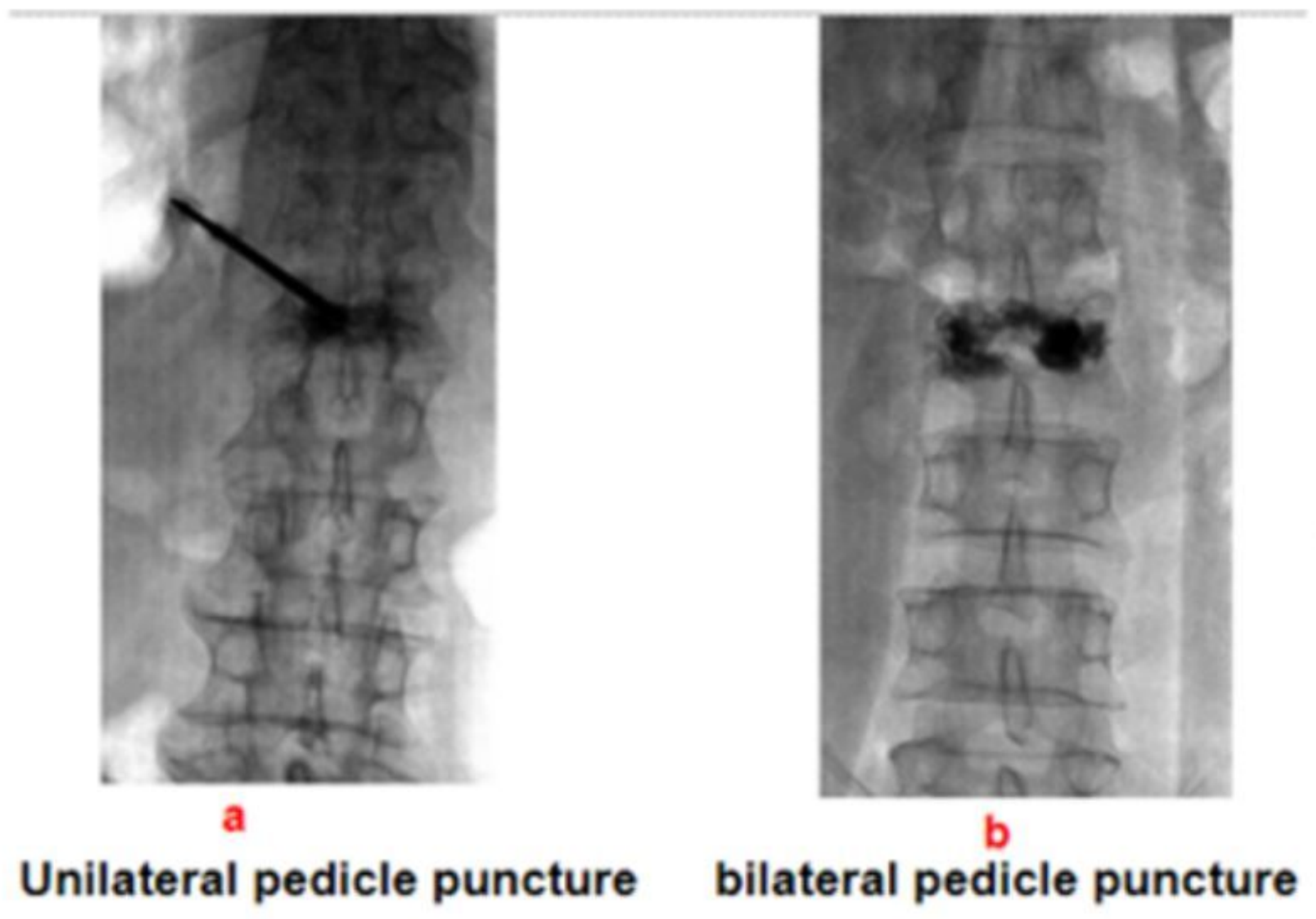

Figure 1

Figure 1 


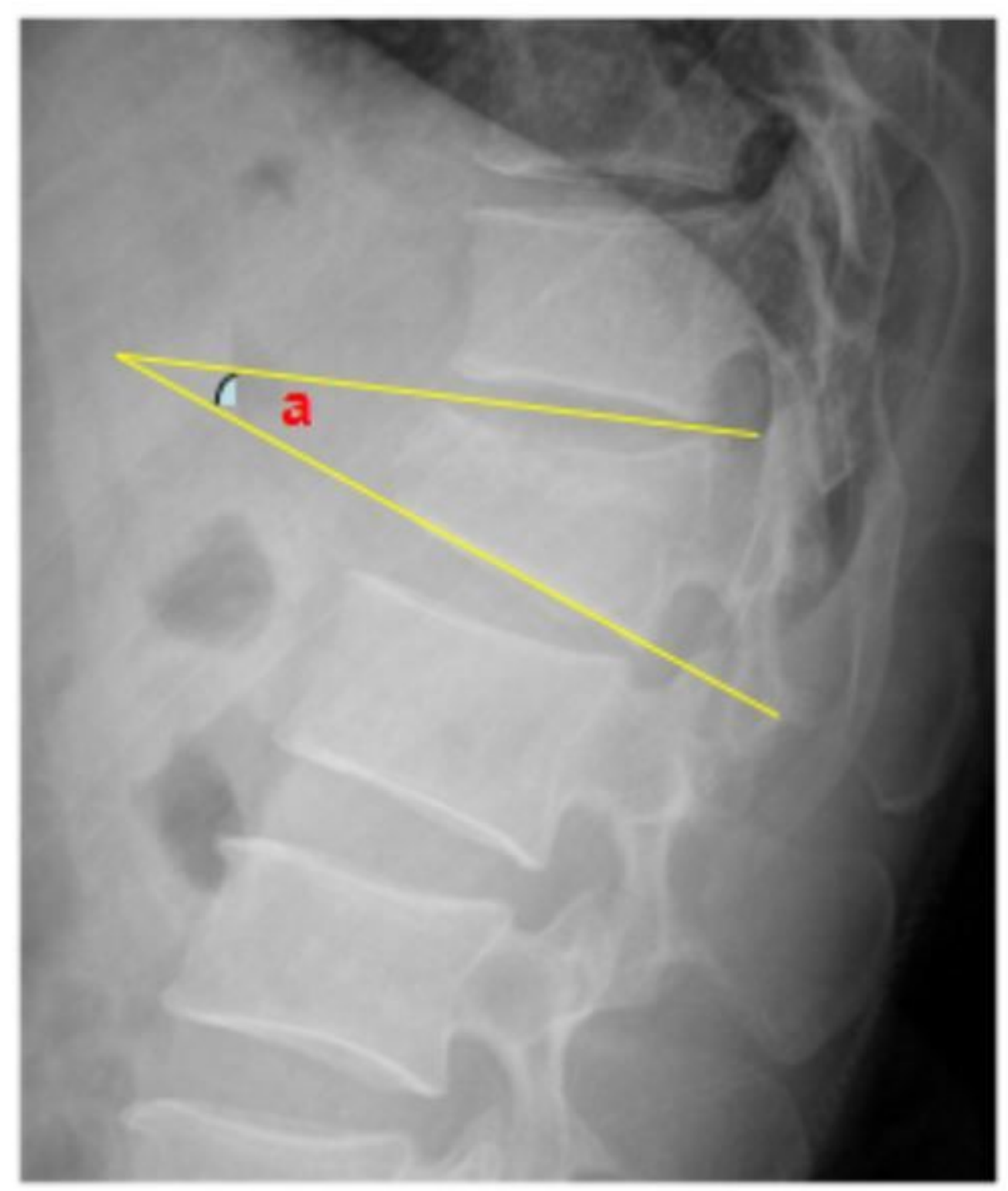

Figure 2

A Kyphosis angle 


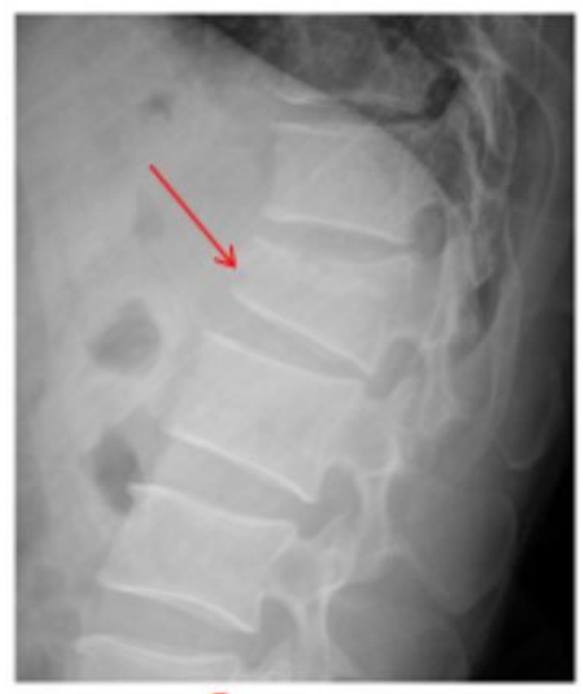

a

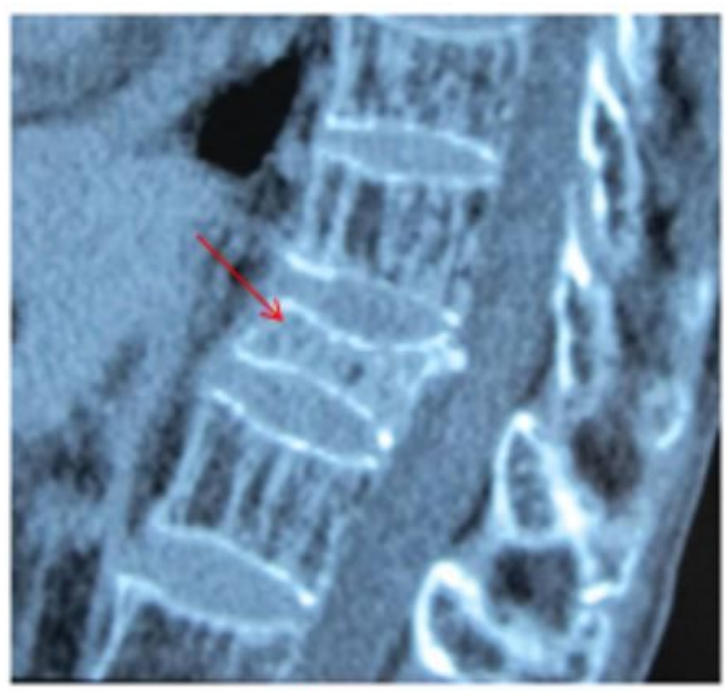

b

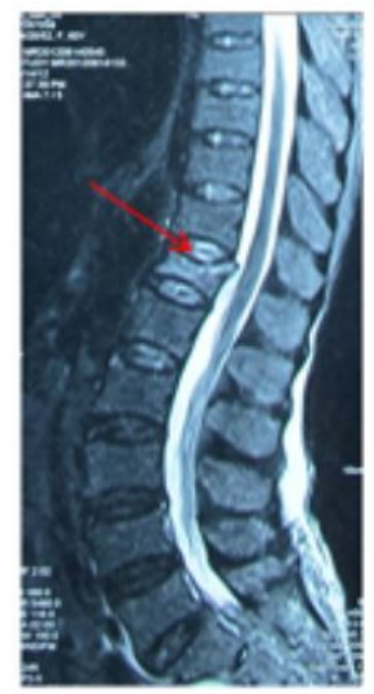

C

Figure 3

Preoperative imaging data.

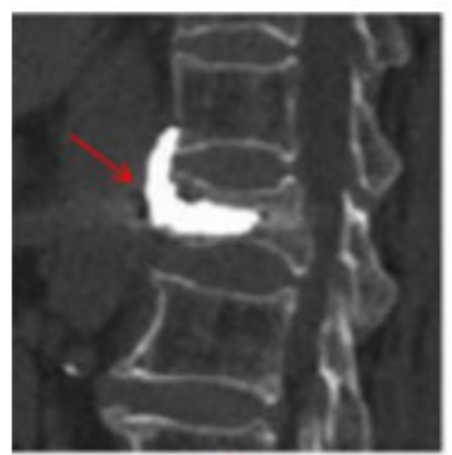

a

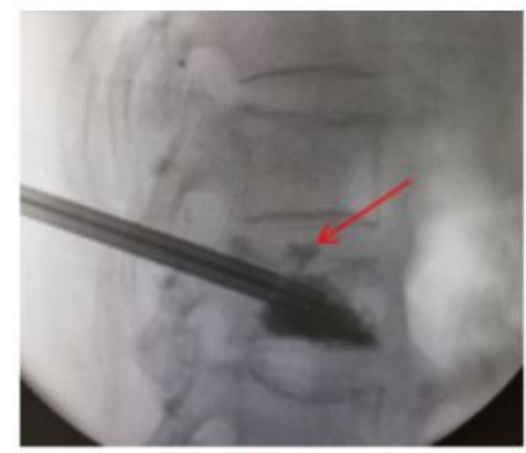

b

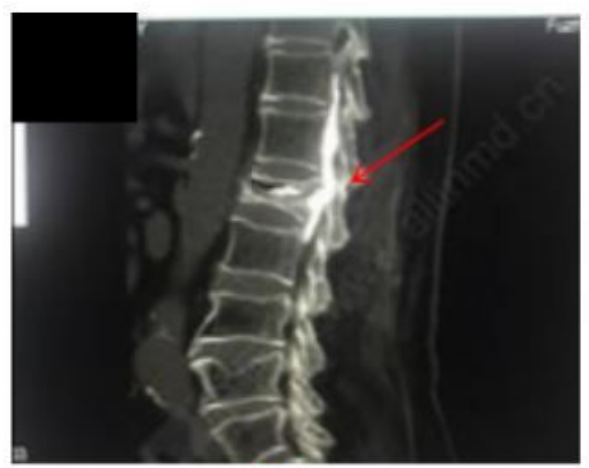

C

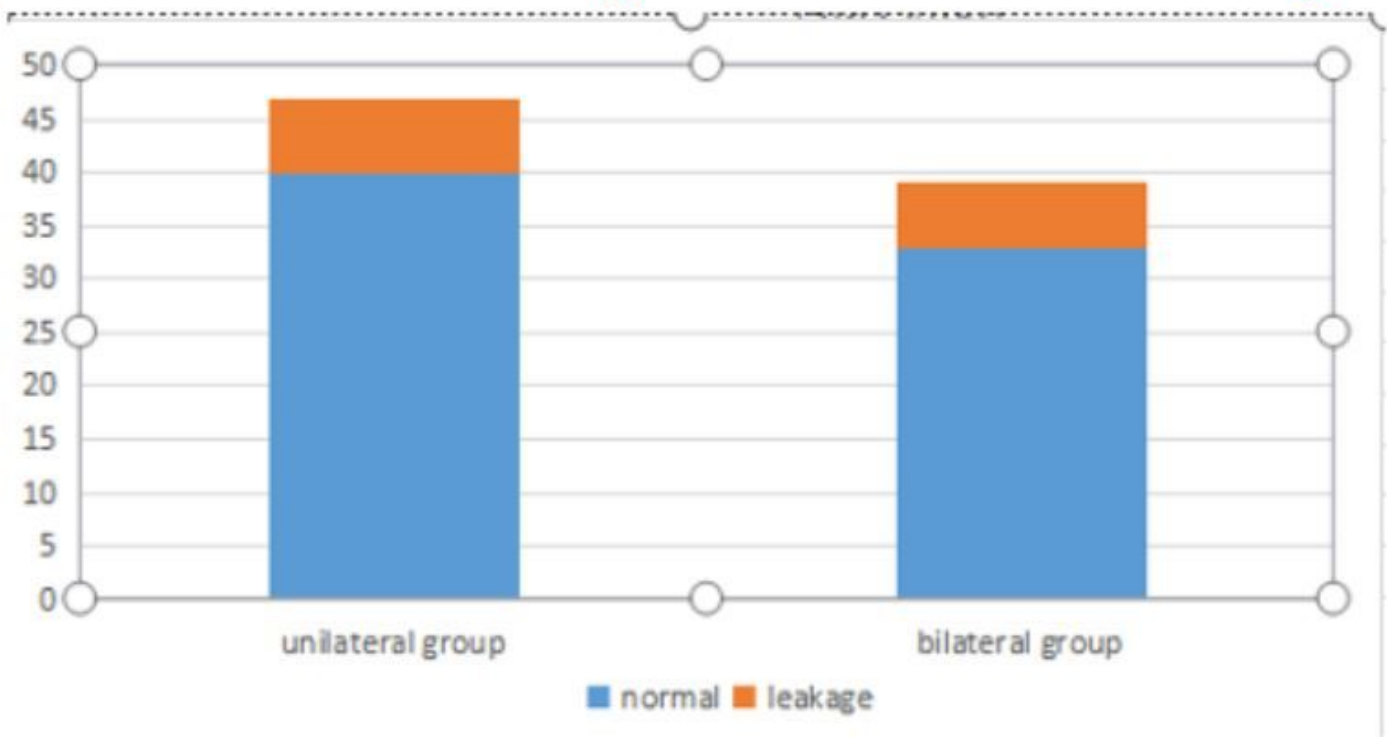

d

Figure 4 
Figure 4

\section{Supplementary Files}

This is a list of supplementary files associated with this preprint. Click to download.

- Tableexplanation.doc

- Pictureexplanation.doc 